\title{
EDUCAÇÃO DO CORPO: PRODUÇÃO E REPRODUÇÃO*
}

\section{EDUCATION OF THE BODY: PRODUCTION AND REPRODUCTION}

Tadeu João Ribeiro Baptista, da Pontifícia Universidade Católica de Goiás Anita Cristina Azevedo Resende, da Universidade Federal de Goiás

\section{RESUMO}

O corpo como objeto de estudos é debatido cada vez mais atualmente. Assim, pretende-se discutir a educação do corpo no capitalismo, sobretudo na sociedade presente. Questiona-se como se determina a forma do corpo na sociedade capitalista atual. O objetivo é identificar como se estabelecem as mediações responsáveis pela determinação da forma do corpo neste modo de produção. O referencial teórico adotado é Karl Marx, Theodor Adorno, Max Horkheimer e Georg Lukács. Este trabalho teórico demonstra que a forma do corpo é determinada pelos interesses relacionados à produção e ao consumo vigentes no modo de produção capitalista.

Palavras-chave: Corpo. Trabalho. Indústria cultural. Educação.

O presente texto é a síntese de uma tese de doutorado em educação, tendo o corpo como objeto de estudos. Este assunto vem sendo discutido desde a antiguidade e estudado em diferentes paradigmas, áreas de conhecimento, ciências e análises as quais demonstram as distintas possibilidades para um tema tão amplo e atual.

Os estudos acerca do corpo têm-se desenvolvido de maneira significativa. Tratase de um tema da filosofia, da arte ou das ciências, desde a medicina até as ciências humanas e sociais. São muitas as possibilidades de compreendê-lo: realizando estudos sobre a sua condição animal (biológica) de existência a partir de uma perspectiva apresentada pela biologia e pela medicina, refazendo-se o percurso das modificações anatômicas do corpo como espécie, por meio de uma discussão evolucionista ou, ainda, discutindo-o em uma perspectiva cultural, na qual o corpo é analisado por sua relação com diferentes áreas de conhecimento vinculadas às humanidades e à história. Esta última pretende ser a perspectiva deste trabalho. Todavia, tendo em vista, inclusive, a discussão existente sobre o corpo, deve-se considerá-lo no âmbito atual como sendo fruto de seu tempo, não se podendo, portanto, comentá-lo apenas como lócus de sua existência física, referente apenas ao trabalho manual ou braçal, mas, acima de tudo, como síntese da história humana, tendo, ainda como referência as condições intelectuais assim como, todas as habilidades e capacidades desenvolvidas por ele.

As distintas análises sobre o tema abrem possibilidades diferenciadas de debate fundadas nos paradigmas epistemológicos das modernas ciências humanas e sociais. Embora existam diferentes abordagens a serem consideradas e demonstradas por diferentes autores, há uma contribuição importante na análise histórica de Marx, para quem o corpo é uma construção histórica, submetido a condições determinadas de acordo com a organização do trabalho. Trabalho esse realizado tanto de maneira manual como intelectual ou provavelmente - seria mais adequado dizer - em condições predominantes de uma dessas formas, tendo em vista a incapacidade de se separá-las empiricamente. Logo, pode-se considerar o corpo como manifestação material e

\footnotetext{
* Artigo recebido em16/11/2008 e aprovado em 11/03/2009.
} 
espiritual da espécie humana. Nessa perspectiva, o suposto fundamental do presente texto é a subordinação do corpo biológico e universal à particularidade histórica do modo de produção capitalista.

Essa subordinação da biologia à história contribui constantemente para diferentes possibilidades corporais constituídas pela forma como o trabalho é realizado. Esse fato dá ao corpo várias possibilidades de crítica e. assim, vários autores já demonstraram este corpo como força de trabalho (SOARES, 2001), como corpo eleito ou explorado (GRANDO, 2001), ou ainda, submetido à racionalidade técnica (SILVA, 2001), e, mesmo, considerando-o uma máquina (DESCARTES, 1973; La Mettrie citado por ROUANET, 2003). Estas demonstrações de como o corpo pode ser analisado sob diferentes aspectos, abordagens e mesmo paradigmas epistemológicos, são fundamentais para sua análise e correspondem a uma parte das análises realizadas.

Todavia, sob a luz do materialismo dialético, existem alguns estudos que configuram o corpo em algumas características como o fetiche e a alienação. Contudo, principalmente entre pesquisadores da educação física ${ }^{1}$, poucos constroem de maneira aprofundada as mediações constitutivas do corpo.

Entre as variadas pesquisas, algumas chegam a descrever o modelo e as características (forma/conteúdo) necessárias à manutenção do modo de produção capitalista de acordo com os seus interesses bem como as estratégias utilizadas para alcançar tais objetivos, entre eles a ginástica e as cirurgias plásticas, apenas para se mencionarem dois exemplos. No entanto, através da revisão de literatura realizada, não se conseguiu identificar até o momento por que se seleciona, do ponto de vista social, uma determinada forma de corpo e não outra, sendo esta a preocupação central do presente texto.

A partir daí, outra questão merece ser problematizada: a constituição de um modelo de corpo como referência em detrimento de outras formas. Do desenvolvimento dessa problemática, surge o problema do presente trabalho: como se determina a forma do corpo na sociedade capitalista atual?

Esse problema explica-se por buscar identificar o nexo que se constitui entre a forma geral do corpo e as exigências históricas do modo de produção capitalista, interesse que se justifica por alguns aspectos centrais.

1. Somente consolidando-se as condições necessárias à reprodução do capital, é possível sustentá-lo historicamente;

2. Esse modo de produção de mercadorias e reprodução da vida em última análise não foi suplantado, permanecendo ainda as suas leis gerais;

3. Partindo-se de uma revisão de literatura, tomando-se referências variadas e, a par da variedade de abordagens encontradas, ainda é necessário questionar a determinação do corpo e suas mediações históricas e materiais.

Por isso, definiu-se ainda como objetivo geral da pesquisa analisar as mediações históricas determinantes da forma do corpo. Entre os objetivos específicos encontramse: a) compreender o trabalho como determinação do modelo de corpo; b) compreender o processo envolvido na esfera da produção e do consumo, e c) discutir como este processo gesta um processo de educação e determinação da forma do corpo. Destarte, a discussão apresentada não perde o corpo como foco central, mas, para atingir os objetivos propostos, é necessário realizar um mergulho em determinadas categorias, como tentativa de explorar os elementos determinantes da forma do corpo natural, portanto biológico e social, simultaneamente. 
Para tanto, foi realizado um trabalho teórico com base em uma pesquisa bibliográfica, a qual possui como referencial teórico os estudos de Karl Marx, Friedrich Engels, Theodor Adorno, Max Horkheimer e Georg Lukács.

Assim sendo, procurou-se construir os elementos centrais para dar sustentação à construção da resposta a partir da divisão do trabalho, em três tópicos: No primeiro, será discutido o papel do trabalho enquanto categoria fundamental para a constituição do ser humano. No segundo, será discutido o corpo no conjunto das relações sociais, dentro do modo de produção capitalista, na sua particularidade e seus desenvolvimentos na alienação, na reificação e no fetiche da mercadoria. No terceiro e último tópico, será discutido o papel da indústria cultural como uma das estratégias adotadas para a disseminação da racionalidade tecnológica da sociedade administrada, contribuindo para a disseminação de um modelo de corpo adestrado. Por fim, pretende-se realizar algumas reflexões a respeito de como todo este processo funciona como um processo educativo do corpo.

\section{O TRABALHO E A CONSTITUIÇÃO DO SER HUMANO.}

Quando se pretende discutir um objeto a partir do materialismo dialético, deve-se focalizar as categorias consideradas fundamentais para a explicação do objeto. No caso da análise do corpo como materialidade da constituição humana, a primeira dessas categorias, e provavelmente a categoria central, é o trabalho. O trabalho é o fundamento constitutivo do ser humano e se torna essencial para se compreender o processo de produção e reprodução da vida, por isso, uma luta radical apresentada pelos homens.

Esta seria a mais difícil e radical luta a ser travada por todos os homens, e por todos os tempos, frente à natureza, aos outros homens e a si mesmo: luta pela constituição e confirmação de sua humanidade. Por seu próprio trabalho, nesta batalha de vida e de morte, o homem criará e recriará sua condição humana, fará e refará seu percurso de forma penosa, lúdica, mágica e limitada. Condenado, racional, pecador e carente, desde sempre encontrará o trabalho como uma determinação fundamental, como a necessária condição de possibilidade, na produção e modificação de seu ser, de sua consciência, enfim, de sua própria humanidade. (RESENDE, 1992, p.33 - grifo nosso)

Para além da batalha de vida e de morte do homem, o trabalho converte-se na condição necessária para a modificação da natureza com a qual interage, do ser e de sua consciência. Dessa forma, o trabalho pode ser compreendido sob dois aspectos: em sua relação com a consciência e na relação e entre consciência e história.

A primeira abordagem, consolidada pelo vínculo entre trabalho e consciência tem como referência a análise proposta por Hegel. Para ele, o trabalho consolida-se pelo agir humano e é, em si, o processo de objetivação humana. Diz o autor que o Trabalho:

[...] é desejo refreado, um desvanecer contido, ou seja, o trabalho forma. A relação negativa para com o objeto torna-se a forma do mesmo, algo permanente, porque justamente o objeto tem independência para o trabalhador. Esse meio-termo negativo, ou agir formativo, é ao mesmo tempo, a singularidade, ou o puro ser-para-si da consciência, que agora no trabalho se transfere para fora de si no elemento do permanecer; a consciência trabalhadora, portanto, chega assim à intuição do ser independente, como [intuição] de si mesma. (HEGEL, 2003, p. 150 - grifos nossos.) 
O processo de trabalho e a objetivação da consciência não só são responsáveis pelo agir humano sobre a natureza, mas, acima de tudo, possibilitam a consolidação da consciência trabalhadora. Para Hegel (2003), a consciência manifesta-se através de suas obras e de sua ação. Quando ela age e se exterioriza na produção do objeto, o produto de sua ação torna-se para ela o local de sua reflexão, a qual pode ser entendida de duas formas. A primeira, no fato de o objeto ser ele um espelho para o seu produtor. Assim, ele não enxerga o objeto produzido, mas, acima de tudo, ele encontra sua consciência refletida na sua produção, fruto de seu trabalho. O segundo aspecto desta reflexão é o fato de ele poder analisar a sua obra, refletir e, por isso, transformar a sua consciência, tornando-se um homem diferente do que era antes. Em outras palavras, apoiadas no pensamento do próprio Hegel (2003), o trabalho constitui a consciência humana, pois, a exteriorização da consciência através do bem produzido permite a sua reflexão e, consequentemente, a transformação do homem.

Partindo da idéia anterior, Hegel demonstra a importância da consciência do trabalhador, pois, apenas trabalhando e transformando o mundo de maneira direta, torna-se possível constituir a consciência. Assim, entre um homem que determina o trabalho e o outro, executor, o autor vai questionar qual é a consciência mais importante, se a do senhor ou a do escravo, fato desenvolvido na sua parábola do senhor e do escravo em Fenomenologia do Espírito. Nessa passagem, Hegel colocará como consciência mais importante a do escravo e não a do senhor, visto ser aquele o realizador do trabalho e não este. Por isso, o escravo é o dono da consciência independente e não o contrário, fato esse aparente na relação entre eles.

Entre o senhor e o escravo existe uma relação manifesta entre as duas consciências: "[...] uma, a consciência independente para a qual o ser-para-si é a essência; outra, a consciência dependente para a qual a essência é a vida, ou o ser para um Outro. Uma é o senhor, outra é o escravo."(HEGEL, 2003, p.147)

Assim, para Hegel (2003), o senhor é, ao mesmo tempo, uma consciência essente, ou seja, uma consciência em si e para si. Da mesma forma, é mediada por outra consciência independente com outra essência ou com a "coisidade em geral." (HEGEL, 2003, p.147). O senhor apresenta suas próprias relações, vincula-se com o escravo devido à independência deste em relação àquele e, por outro lado, por meio da dependência do escravo. Usando outras palavras do próprio autor, o senhor, em relação ao seu escravo, possui duas características, sendo elas a potência e o gozo. Potência, por estar acima do escravo, sendo este uma coisa através da qual, o senhor se relaciona para alcançar seus fins; e gozo, por conseguir o que desejava (HEGEL, 2003).

Por outro lado, o senhor consegue, através do seu escravo, estabelecer a relação entre ele e as coisas, ou seja, o escravo é o instrumento de apropriação da coisa ou do objeto pelo senhor. Hegel apresenta esta explicação da seguinte maneira:

O senhor também se relaciona mediatamente por meio do escravo com a coisa; o escravo, enquanto consciência-de-si em geral, se relaciona negativamente com a coisa, e a suprassume. Porém, ao mesmo tempo, a coisa é independente para ele, que não pode portanto, através do seu negar, acabar com ela até a aniquilação; ou seja, o escravo somente trabalha. Ao contrário, para o senhor, através dessa mediação, a relação imediata vem-a-ser como a pura negação da coisa, ou como gozo - o qual the consegue o que o desejo não o conseguia: acabar com a coisa e aquietar-se no gozo. $\mathrm{O}$ desejo não conseguia por causa da independência da coisa; mas o senhor introduziu o escravo entre ele e a coisa, e assim, se conclui somente com a dependência da coisa, e 
puramente a goza enquanto o lado da independência deixa-o ao escravo que trabalha. (HEGEL, 2003, p.148 - grifo nosso)

Neste primeiro momento, cabe apenas ao escravo o trabalho, pois este manifesta a independência do senhor em relação ao escravo, o qual "[...] somente trabalha" (HEGEL, 2003, p.148.). Nesta relação entre o senhor e o escravo, existe, ao menos aparentemente, um domínio do senhor sobre o seu escravo, visto como o primeiro se apropria da natureza e de todos os objetos através do trabalho do segundo.

E, ainda, o senhor, em sua consciência-de-si, considera-se essencial, enquanto a consciência do escravo, mesmo sendo outra consciência-de-si, é inessencial para o senhor, pois, a princípio, o escravo só trabalha ().

Todavia, essa idéia do inessencial do escravo esconde uma armadilha. $\mathrm{O}$ reconhecimento dos objetos apreendidos pelo senhor para a consciência-de-si, através do trabalho realizado pelo escravo, permite ao senhor um reconhecimento unilateral e desigual, pois, "[...] o escravo faz sobre si o que também faria sobre o Outro" (HEGEL, 2003, p.148) Nessa consciência feita inessencial para o senhor, possibilita-se o reconhecimento de sua própria consciência. Entretanto, há de se observar o fato de haver uma relação de dominação entre o senhor e o escravo, e o primeiro reconhecer-se pelo trabalho do outro, pois é ele - o senhor - quem determina a ação a ser realizada. Há, nesse caso, uma aparente noção de independência. Todavia, essa independência do senhor é falsa. A verdadeira liberdade encontra-se, na realidade, com o escravo e não com o senhor. Este fato é justificado, pois:

[...] a consciência escrava é consciência-de-si, e importa agora considerar o que é em si e para si mesma. Primeiro, para a consciência escrava, o senhor é a essência; portanto, $a$ consciência independente para si essente é para ela a verdade; contudo, para ela [a verdade] ainda não está nela, muito embora tenha de fato nela mesma essa verdade da pura negatividade e do ser-para-si; pois experimentou nela essa essência. Essa consciência sentiu a angustia, não por isto ou aquilo, não por este ou aquele instante, mas sim através de sua essência toda, pois sentiu o medo da morte, do senhor absoluto. Aí se dissolveu interiormente; em si mesma tremeu em sua totalidade; e tudo que havia de fixo, nela vacilou. (HEGEL, 2003, p. 149 - grifos no original)

A dominação apresentada entre o senhor e o escravo é, aparentemente, mediadora apenas da consciência do senhor, responsável pela determinação do "trabalho" a ser realizado pelo escravo, ao mesmo tempo se apropriando dos objetos. Mas, isso é uma falsidade, haja vista a dominação neste processo ser inversa, tendo-se como referência o fato de escravidão representar o seu oposto. É o contrário da aparência imediata, pois, na essência, a consciência repelida do escravo sobre si mesma vai demonstrar a sua autêntica independência.

Em um primeiro momento, o escravo se "reconhece" em seu senhor e teme a sua morte pela aniquilação realizada pelo senhor.

O senhor, segundo Hegel, é o homem que leva até o fim, arriscando sua vida, na luta pelo reconhecimento. O escravo é o homem que, por medo da morte, recua na luta e renuncia a ser reconhecido. Arriscando sua vida natural, biológica, o senhor alcança, algo verdadeiramente espiritual, para salvar seu ser natural biológico. Assim, o senhor fica num plano propriamente humano, o escravo não. (VÁZQUEZ, s.d., p.75) 
Neste momento, a consciência do escravo não atinge o plano da humanidade, pois, a sua consciência é dependente, porquanto, o "[...] agir do escravo não é um agir puro, mas um agir inessencial." (HEGEL, 2003, p. 148)

Ao realizar os desejos do senhor, o escravo se reconhece a si mesmo através da consciência de seu senhor, pois a consciência deste é dependente daquele e, ainda, o aparentemente inessencial para as consciências - o papel do trabalho realizado pelo escravo - é compreendido inicialmente como um simples servir (HEGEL, 2003).

\section{Entretanto,}

[...] o sentimento de potência absoluta em geral, e em particular o do serviço, é apenas a dissolução em si; e embora o temor do senhor seja, sem dúvida, o início da sabedoria, $a$ consciência aí é para ela mesma, mas não é o ser-para-si; porém encontra-se a si mesma por meio do trabalho. No momento que corresponde ao desejo na consciência do senhor, parecia caber à consciência escrava o lado da relação inessencial para com a coisa, porquanto ali a coisa mantém sua independência. $\mathrm{O}$ desejo se reservou o puro negar do objeto e por isso o sentimento-de-si-mesmo, sem mescla. Mas essa satisfação é pelo mesmo motivo, apenas um evanescente, já que lhe falta o lado objetivo ou o subsistir. (HEGEL, 2003, p.150 - grifo nosso)

Está em causa a construção da autoconsciência existente na potência da atitude do senhor de arriscar a própria vida, apesar do natural medo da morte que se tem. Todavia, ao defrontar-se com essa situação, a noção do desejo por parte do senhor o faz negar o objeto e, assim, reafirmar não só a sua consciência-de-si, mas também a consciência para si, encontrada através do trabalho. Constitui-se, então, a independência da consciência do próprio escravo. Para entender essa relação, pode-se dizer que

o trabalho é servidão, dependência em relação ao senhor, mas essa dependência acarreta - como atividade prática, real - a transformação da natureza e a criação de um produto. $O$ subjetivo se torna objetivo no produto e, desse modo, cria um mundo próprio. $\mathrm{O}$ produto de seu trabalho já não é um em si, mas um para si. É possível reconhecer-se nos produtos que criou, transformando a natureza, o escravo reconhece a sua própria natureza. (VÁZQUEZ, s.d., p.75 - grifo nosso).

A servidão presente no trabalho acarreta por sua vez uma atividade prática, a qual permite a quem a realiza, no caso o escravo, a transformação da natureza. Ao realizar essa transformação, o escravo constrói objetivamente o produto de seu empenho, mesmo sendo realizado a partir das ordens do seu senhor. Ainda assim, permitirá o reconhecimento de seu esforço. O trabalho gera, então, o produto para si, no qual o escravo se reconhece por ter transformado a natureza com suas mãos. Destarte, o escravo reconhece a sua própria natureza; por isso, sua consciência torna-se independente frente à consciência do seu senhor. Assim, partindo-se dessa análise, o trabalho, em seu contexto de universalidade, permite o reconhecimento - subjetivação do seu realizador, separadamente da sua posição no processo produtivo.

O trabalho, conforme vem sendo demonstrado, vai, progressivamente mudando de feição. A servidão inicial contempla apenas o desenvolvimento da consciência do senhor, ser superior determinante das coisas e, por isso, é independente em sua autoconsciência, vai com o desenvolvimento das relações, invertendo-se. Ao transformar a natureza - aspecto mais bem desenvolvido por Marx, posteriormente -, o 
trabalho adquire objetividade a partir de relações subjetivas; porquanto, ao trabalhar, o escravo coloca no produto sua própria consciência. "Êsse reconhecimento de si em seus produtos é consciência de si como ser humano. O escravo se liberta de sua própria natureza ao libertar-se, mediante o trabalho da natureza exterior" (VÁZQUEZ, s.d., p.75).

Em todo esse processo, o trabalho, como forma de objetivação humana, acaba por elaborar a autoconsciência para o seu produtor direto. A consciência de quem trabalha torna-se livre, independente. Quem não cria e não transforma, ou seja, não trabalha, não pode ser livre. Assim sendo, o trabalho realizado pelo escravo transforma a sua consciência, libertando-o, transformando-o em ser essencial, em consciência essencial. Ao mesmo tempo, o senhor, aparentemente independente, torna-se dependente de seu escravo, pois a falta de realização de trabalho por sua parte faz dele um ser sem condições de reconhecer-se nos seus próprios produtos, conforme é discutido por Hegel (2003).

Desse modo, o seu reconhecimento se faz pelo ser-Outro, responsável pela produção dos objetos do interesse do senhor, os quais servem para o seu gozo - o escravo. Assim, enquanto “[...] o senhor, por não criar, por não transformar coisas, não se transforma a si mesmo e não se eleva, portanto, como ser humano, o escravo se eleva como tal e adquire consciência de sua liberdade, não à realização desta" (VÁZQUEZ, s.d., p. 75). Destarte, existe uma inversão na consciência dependente e independente, do senhor e do escravo, sendo a deste último mais importante.

Desse modo, Hegel é um dos primeiros autores modernos a demonstrar a importância do trabalho como fundamento das relações sociais e construção do homem, todavia, existe nesse autor uma inversão. Marx discute a respeito do trabalho partindo das contribuições de Hegel.

O grande mérito da Fenomenologia de Hegel e do seu resultado final - a dialética da negatividade enquanto princípio motor e criador - reside, em primeiro lugar, no fato de Hegel conceber a autocriação do homem como processo, a objetivação como perda do objeto, como alienação e como abolição da alienação; e no fato de ainda apreender a natureza do trabalho e conceber o homem objetivo (verdadeiro, porque homem real), como resultado do seu próprio trabalho. A orientação real, ativa, do homem pra si mesmo enquanto ser genérico ou a fixação por si próprio como ser genérico real, quer dizer, como ser humano, só é possível à medida que ele realiza todos os seus poderes específicos - o que, por sua vez, só é possível através da ação coletiva dos homens e como resultado da história - e trata estes poderes como objetos. Mas isto só é viável na forma de alienação. (MARX, 2002, p.178 - grifo no original).

Assim sendo, Hegel explica o elo existente entre o trabalho e a consciência, contudo, desconsidera "[...] a ação coletiva dos homens e como resultado da história [...]" (MARX, 2002, p.178) Ao considerar a história e a ação entre os homens, Marx apresenta, da seguinte forma, outra concepção de trabalho:

antes de tudo, o trabalho é um processo entre o homem e a Natureza, um processo em que o homem, por sua própria ação, media, regula e controla seu metabolismo com a Natureza. Ele mesmo se defronta com a matéria natural como uma força natural. Ele põe em movimento as forças naturais pertencentes a sua corporalidade, braços e pernas, cabeça e mão, a fim de apropriar-se da matéria natural numa forma útil para sua própria vida Ao atuar, por meio desse movimento sobre a Natureza externa a ele e ao modificá- 
la, ele modifica, ao mesmo tempo, sua própria natureza. Ele desenvolve as potências nela adormecidas e sujeita o jogo de suas forças a seu próprio domínio. (MARX, 1996, p.297 - grifo nosso).

Ao considerar o trabalho como a ação metabólica existente entre o homem e a natureza e compreendendo essa natureza como já tocada pelo homem, o autor identifica a natureza como humana, e, portanto histórica, assim como compreende o homem como ser natural. Considerar esse aspecto significa situar a consciência do corpo e o corpo da consciência, pois o ser natural, bem como a sua existência, só se tornam possíveis pelo corpo, lócus da existência humana.

Contudo, Marx submete a história e por isso o próprio trabalho à forma como o modo de produção se organiza e, ao fazê-lo, compreende a organização das relações sociais submetidas ao processo mercantil. Tendo-se em vista, o fato de a vida ser submetida, neste momento, ao modo de produção capitalista, ao invés do trabalho constituir o ser humano em sua plenitude, ele se torna responsável pelo desenvolvimento da alienação, do fetiche e da reificação.

\section{CORPO: ALIENAÇÃO, REIFICAÇÃO E FETICHE}

Conforme foi discutido na seção anterior, o trabalho sob as condições gerais de realização constitui a consciência humana. Contudo, sob as condições capitalistas, o trabalho configura outros processos, o primeiro deles, a alienação.

De maneira sintética, pode-se identificar a alienação com quatro dimensões, as quais vão aprofundando-se e apresentando níveis mais complexos para o ser humano. De acordo com Marx (2002), a alienação pode manifestar-se pela alienação do produto desenvolvido pelo indivíduo, o qual não se reconhece naquele. $\mathrm{O}$ objeto fabricado torna-se estranho, conforme Hegel (2003), embora o trabalho não deixe de ser uma forma de objetivação do homem. O processo de objetivação é comentado por Marx:

[...] o objeto produzido pelo trabalho, o seu produto, opõe-se a ele como um estranho, como um poder independente do produtor. O produto do trabalho é o trabalho que se fixou num objeto, que se transformou em coisa física, é a objetivação do trabalho. $A$ realização do trabalho constitui simultaneamente a sua objetivação. (MARX, 2002, p.111-2 - grifo nosso)

Essa objetivação realizada pelo trabalho poderia ser considerada um aspecto ontológico em diversas situações, como demonstra Hegel (2003) na parábola do senhor e do escravo, quando este se realiza e se reconhece ao produzir os objetos determinados pelo senhor. Este objeto produzido retorna à consciência, provocando a subjetivação de seu produtor e não de quem ordenou a produção.

A alienação é estabelecida, nessas condições, pelo fato inicial de o trabalho fixarse no produto e lá permanecer. A princípio, esta é a objetivação do trabalho, pois isso acontece em qualquer situação. Contudo, aqui, o artefato é simples objetivação, não havendo então o segundo momento comentado por Hegel (2003): o da subjetivação, no qual o produto elaborado seria a fonte do reconhecimento do seu produtor, ou ainda, no modo de produção capitalista, do reconhecimento do trabalhador.

O trabalho (assim como o seu fruto) realizado pelo indivíduo torna-se uma desrealização do ser, porquanto se encontra aí "[...] a objetivação como perda e a servidão do objeto, a apropriação como alienação" (MARX, 2002, p.112). Por isso, 
identifica-se a objetivação como servidão, pois o indivíduo não consegue realizar-se no fruto produzido, visto que ele não retornou para si. Destarte, quando o indivíduo coloca-se em um objeto, o qual não retorna para a sua consciência, o reconhecimento de si no produto de seu trabalho desaparece. A subjetivação ocorrida pela reflexão do produto para seu produtor não acontece. Desenvolve-se, neste caso, um primeiro processo da alienação. Aqui,

O trabalhador põe a sua vida no objeto. Quanto maior a sua atividade, mais o trabalhador se encontra no objeto. O que se incorporou no objeto do trabalho já não é seu. Assim, quanto maior é o produto, mais ele fica diminuído. A alienação do trabalhador no seu produto significa não só que o trabalho se transforma em objeto, assume uma existência externa, mas que existe independentemente, fora dele e a ele estranho, e se torna um poder autônomo em oposição a ele; que a vida que deu ao objeto se torna uma força hostil e antagônica. (MARX, 2002, p.112)

Nesse processo de alienação, o estranhamento ocorre pelo não retorno do objeto para o sujeito (o produtor neste processo). O objeto toma vida própria e, por isso, parece emancipar-se, dando inclusive a noção de sempre ter existido independentemente da produção humana. A aparência, nesse caso, é de o objeto anteceder o sujeito e ter a sua vida independente dele. Em sua exterioridade, essa coisa autônoma assemelha-se a outras coisas com as quais se relacionou para a reprodução e, dessa maneira, o produtor fica totalmente subsumido nessa relação.

Todavia, esse nível de alienação - em relação ao objeto do trabalho - é apenas a primeira parte de um processo mais denso, pois, quando o trabalhador deixa de ser o dono dos artigos produzidos por ele, o mesmo tende a perder também a compreensão do processo. Pela alienação do processo, a atividade laboral passa a ser trabalho forçado.

Assim, o seu trabalho não é voluntário, mas imposto, é trabalho forçado. Não constitui a satisfação de uma necessidade, mas apenas um meio de satisfazer outras necessidades. O trabalho externo, o trabalho em que o homem se aliena, é um trabalho de sacrifício de si mesmo, de martírio. O seu caráter estranho resulta visivelmente do fato de se fugir do trabalho, como da peste, logo que não existe nenhuma compulsão física ou de qualquer outro tipo. (MARX, 2002, p.114 - grifo do autor)

Se o trabalho deve constituir-se como o fundamento de consolidação do ser humano e, se sob o modo de produção capitalista, o trabalhador perde o produto de seu labor, o processo se converte em trabalho forçado e não satisfação das suas necessidades. Existe uma tendência de que o proletário perca a si mesmo, num terceiro momento, o qual pode ser considerado auto-alienação.

Tal relação é a relação do trabalhador com a própria atividade assim como com alguma coisa estranha, que não lhe pertence, a atividade como sofrimento (passividade), a força como impotência a criação como emasculação, a própria energia física e mental do trabalhador, a sua vida pessoal - e o que será a vida senão atividade? - como uma atividade dirigida contra ele, independente dele que não lhe pertence. Esta é a autoalienação, em contraposição com a acima mencionada alienação da coisa (MARX, 2002, p. 115 - grifos no original). 
Essa auto-alienação ou a alienação de si do trabalhador acaba por se aproximar de um último nível do processo, a alienação em relação aos outros homens. Este fato acontece pelo trabalhador compreender-se apenas um apêndice da máquina, ele passa a ver os outros seres humanos como máquinas, por isso as relações não são mais entre homens, mas entre coisas.

Se o ser humano converte-se em coisa e está subsumido às relações mercantis de produção ele tende a se converter em força de trabalho e, portanto, em mercadoria. Toda mercadoria possui valor. Esse valor é, primeiro, valor de $u^{2}{ }^{2}$, quando o produto é utilizado pelo seu produtor e proprietário. Em outro momento, ela se converte em valor de troca.

O valor de troca aparece, de início, como a relação quantitativa, a proporção na qual valores de uso de uma espécie se trocam contra valores de uso de outra espécie, uma relação que muda constantemente no tempo e no espaço. O valor de troca parece, portanto, algo casual e puramente relativo, um valor de troca imanente, intrínseco à mercadoria (valeur intrinsèque), portanto um contradictio in adjecto. (MARX, 1996, p.166 - grifos no original)

O valor de troca é fundamental na determinação do valor da mercadoria, porquanto qualquer bem de consumo só se converte em mercadoria quando possui valor de troca. Todavia, o valor de troca cria as bases para o desenvolvimento do valor. $\mathrm{O}$ valor esconde o elemento fundamental para a determinação da mercadoria: o trabalho humano. Dessa forma, a equivalência do valor das mercadorias depende da quantidade de trabalho humano necessário à sua produção. O que se dá

[...] por meio do quantum nele contido da substância constituidora de valor, o trabalho. A própria quantidade de trabalho é medida pelo seu tempo de duração e o tempo de trabalho possui, por sua vez, sua unidade de medida nas determinadas frações de tempo, como hora, dia, etc. (MARX, 1996, p.168 - grifo do autor).

Desse modo, pode-se compreender o fato de que a substância fundamental à determinação do valor é o quantum de trabalho humano contido em cada mercadoria.

[...] os trabalhos se equiparam mediante a subordinação do homem à máquina ou pela divisão extrema do trabalho; que os homens se esfumam ante o trabalho; que o balançar do pêndulo se tornou a medida exata da velocidade de duas locomotivas. [...] Já não se levanta o problema da qualidade. A quantidade decide tudo: hora por hora, dia por dia [...]. (MARX, 2001, p.48-9)

Esse valor, calculado pelo relógio, na velocidade e na subordinação do homem à máquina, passa a adquirir um caráter fantasmagórico, por isso, fetiche. Para Marx (1996), o fetiche é manifestação da essência da mercadoria.

Aqui, os produtos do cérebro humano aparecem dotados de vida própria, figuras autônomas, que mantêm relações entre si e com os homens. Assim, no mundo das mercadorias, acontece com os produtos da mão humana. Isso eu chamo o fetichismo que adere aos produtos de trabalho, tão logo são produzidos como mercadorias, e que, por isso, é inseparável da produção de mercadorias. 
Esse caráter fetichista das mercadorias provém, como a análise precedente já demonstrou, do caráter social peculiar do trabalho que produz mercadorias. (MARX, 1996, p. 198-9 - grifo nosso)

Assim, pode-se perceber a relação existente entre a mercadoria e o desenvolvimento das figuras fantasmagóricas aderindo aos produtos de trabalho e inseparável da produção. Retomando-se o trabalhador como força de trabalho e ao compreendê-lo como mercadoria, inclusive fetichizada, vinculando-o ainda ao processo de alienação, alcança-se o máximo da relação produtiva: a reificação.

A reificação é anunciada por Marx, mas é mais bem desenvolvida por Lukács. A principal característica da reificação é a transformação do trabalhador e, sobremodo, de sua consciência em coisa. Essa coisa mecaniza-se racionalmente e penetra a alma do trabalhador. Todavia, a lógica da reificação atinge o proletário, o técnico e o dono dos meios de produção, com diferenças quantitativas e não qualitativas. Assim, o indivíduo produzido no modo de produção capitalista se atomiza.

Para Resende (1992), a reificação se desenvolve apoiada em três pontos centrais, sendo eles: a) perda do sentido da totalidade; b) progressiva racionalização e, finalmente; c) transformação da estrutura da consciência.

Todavia, segundo Goldmann (1979), o processo de reificação estende-se para todas as esferas da vida humana, entre elas a própria existência corporal. Contudo, para se disseminar esta idéia, é necessário usar-se uma série de mecanismos para disseminação desse ideário, dentre a família, a religião e, principalmente, a indústria cultural.

Para assegurar o processo de reificação em sua condição plena, o ser humano deve ser controlado em várias esferas de sua vida, entre elas, na sua expressão material e espiritual - o corpo. Este, por sua vez, compreendido como força de trabalho, insere-se na perspectiva de qualquer mercadoria, possuindo um valor de fetiche.

O corpo é a mercadoria a ser trabalhada, alienada, fetichizada e reificada. É ele o responsável direto pela produção como força de trabalho e condições de se rebelar. Evitar a rebelião e garantir o processo produtivo e reprodutivo do capital são objetivos a serem considerados, sendo por isso necessário um aprofundamento das análises dessas condições para ser possível revelar a ação do capital.

Partindo-se, então, dos interesses do modo de produção, das exigências do processo produtivo e da necessidade de produção de mercadorias, o trabalhador, em sua condição material de existência - o corpo -, precisa manter-se em condições, inclusive de saúde, adequadas para realizar o seu trabalho e sua troca por outra mercadoria - o dinheiro. Assim, a partir do desenvolvimento da mercadoria, o corpo também precisa gerar valor. Desse modo, compreender o corpo como mercadoria necessária ao processo produtivo, à qual precisa agregar valor, culminará na forma do corpo determinada por esta sociedade, de acordo com as capacidades necessárias para se produzir capital.

Logo, se o corpo possui padrões de referência, se a ele pode-se agregar valor tal e qual a uma mercadoria qualquer, ele deve ser entendido dentro da constituição do seu valor, partindo-se do seu valor de uso ao seu valor como fetiche. Conforme será explicitado a respeito do valor da mercadoria nos parágrafos a seguir, as mediações sobre o corpo adquirem o movimento de consolidação de uma mercadoria como outra qualquer.

Primeiro, corpo é um produto histórico e, assim, como qualquer outro objeto natural, possui as marcas de seu tempo e, por isso, deve atender às demandas 
apresentadas pelo processo de trabalho. Para Marx (1986), mesmo no modo de produção capitalista, o corpo é produto das suas condições materiais de existência, conforme discutem Marx e Engels (1998), não obstante as condições específicas do capitalismo. Contudo, a disseminação da forma do corpo mercadoria depende, entre outras coisas, da disseminação das idéias inerentes ao modo de produção e sua organização, fato este determinado pela indústria cultural.

INDÚSTRIA CULTURAL: RACIONALIDADE TÉCNICA E DETERMINAÇÃO DA FORMA DO CORPO.

A indústria cultural é uma das principais formas de disseminação do ideário capitalista na sociedade atual. Seus mecanismos de ação, sua lógica e sua capacidade de cooptação são fundamentais para se compreenderem os impactos que ela provoca na vida humana. Para se compreender melhor o lugar de onde se fala, a indústria cultural pode ser definida como:

[...] um instrumento de pressão da sociedade sobre o indivíduo através da utilização de elementos culturais que se tornam acessíveis pelo cinema, pela televisão e por outros meios de comunicação de massa. Esses são utilizados como formas de cooptarem os indivíduos para uma atuação de acordo com os interesses e as necessidades do modo de produção, fazendo a lógica industrial prevalecer não apenas nos momentos de trabalho, como também nas horas de repouso de cada pessoa. (BAPTISTA, 2001, p.74).

A indústria cultural é fundamental por ser ela um mediador essencial na relação entre a produção e a reprodução da sociedade, contribuindo, ao mesmo tempo para a manutenção da relação entre produção e consumo. A indústria cultural irá funcionar assim, como um processo responsável pela consolidação e disseminação do modo de produção capitalista.

A indústria cultural, conforme vem sendo discutido, é um dos mecanismos mais avançados utilizados pelo modo de produção como forma de garantir a sua condição de produção e reprodução. A sua capacidade de convencimento é usada pelo capitalismo para garantir as condições necessárias à sua produção e reprodução simultâneas, embora existam outras estratégias eficientes, como a família, a escola e a religião. A indústria cultural se torna mais eficiente porque ela pode: 1) abranger uma maior quantidade de pessoas simultaneamente e 2) a própria racionalidade tecnológica propiciada pelo capitalismo é adotada em larga escala por ela, permitindo, ao mesmo tempo, garantir a instrumentalização da razão no meio social e demonstrar as benesses dos avanços da tecnologia, apresentando-os como progresso sempre positivo. Contudo, para Adorno (1995), o progresso nem sempre é sinônimo de melhoria, principalmente para a classe trabalhadora. Este processo diretamente atrelado aos meios de comunicação depende de algumas condições básicas para o seu funcionamento, que permite não só a disseminação de uma determinada lógica, como também da produção e circulação de mercadorias a serem comercializadas.

Todo este processo depende não apenas da tecnologia, mas, acima de tudo, da razão dominada pela técnica, gerando, inclusive, novas necessidades, demonstrando o nível de coesão do sistema através da racionalidade técnica. 
O que não se diz é que o terreno no qual a técnica conquista seu poder sobre a sociedade é o poder que os economicamente mais fortes exercem sobre a sociedade. A racionalidade técnica hoje é a racionalidade da própria dominação. Ela é o caráter compulsivo da sociedade alienada de si mesma. Os automóveis, as bombas e o cinema mantêm coeso o todo e chega o momento em que seu elemento nivelador mostra sua força na própria injustiça à qual servia. Por enquanto, a técnica da indústria cultural levou apenas à padronização e à produção em série, sacrificando o que fazia a diferença entre a lógica da obra e a do sistema social. Isso, porém, não deve ser atribuído a nenhuma lei evolutiva da técnica enquanto tal, mas à sua função na economia atual. A necessidade que talvez pudesse escapar ao controle central já é recalcada pelo controle da consciência individual. (ADORNO; HORKHEIMER, 1985, p. 114) (Grifo nosso)

A racionalidade técnica é um dos elementos mais fortes no desenvolvimento da coesão do sistema, pois ela permite o processo de dominação de maneira mais efetiva. A padronização da produção é transferida para a dimensão da reprodução da vida. $O$ sistema faz acreditar nesta como sendo a única opção a ser posta. Dessa forma, facilitase o processo da administração da sociedade, obedecendo a uma razão que não compreende.

Existem alguns pontos a serem aprofundados. Primeiro, a racionalidade técnica faz parte da lógica da dominação da sociedade principalmente através do poder econômico. Afinal, o capitalista tem plenas condições de controlar a vida dos trabalhadores, visto que eles determinam o valor da mercadoria da força de trabalho, através da qual mantém as condições de domínio, pois:

A formalização da razão é a mera expressão intelectual do modo de produção maquinal. O meio é fetichizado: ele absorve o prazer. Assim como o esclarecimento transformava teoricamente em ilusões os objetivos com que se adornava a antiga dominação, assim também ele os priva, com a possibilidade da abundância, de seu fundamento prático. A dominação sobrevive como fim em si mesmo, sob a forma de poder econômico. (ADORNO; HORKHEIMER, 1985, p.100)

A razão adota a condição estrutural nos processos apresentados pela indústria cultural, manifestando dois pontos: a) a razão não tem como fugir da lógica da máquina, a qual, por sua vez, é a grande referência para o funcionamento da sociedade. Esta absorve o prazer, tornando-o objeto e fazendo promessas às quais não pode nem pretende cumprir e b) o domínio apresentado pela indústria cultural fundamenta-se necessariamente no emprego do poder econômico. Ao menos na sociedade capitalista, os donos dos meios de produção controlam as relações sociais e, dentro delas, o próprio modelo de cultura, de vida, de corpo a ser consumido por todos.

O outro aspecto a ser considerado é a padronização pela qual passam todos os elementos da indústria cultural, possível através da técnica desenvolvida pela ciência e pela indústria. Ela é a responsável pelo desenvolvimento de um ar de semelhança entre as mercadorias, mesmo de diferentes indústrias. A evidência deste fato é assim apresentada pelos autores:

a diferença entre a série Chrysler e a série General Motors é no fundo uma distinção ilusória, como já sabe toda criança interessada em modelos de automóveis. As vantagens e desvantagens que os conhecedores discutem servem apenas para perpetuar 
a ilusão de concorrência e da possibilidade de escolha. (ADORNO; HORKHEIMER, 1985, p.116)

A concorrência das indústrias entre si é ilusória. Devido ao processo de produção em série, as formas são praticamente idênticas no processo. Assim, a lógica embutida nesse processo é, acima de tudo, fantasiosa e serve apenas como ideologia de controle da sociedade através da razão inerente a ela.

Por meio dos elementos presentes nessa rápida análise da indústria cultural e, principalmente, na sua capacidade de dar a tudo um ar de semelhança, a mesma consegue alcançar também o corpo, haja vista possuir também esse um ar de semelhança. Ele tem, com efeito, como características valorizadas a magreza, expressa no baixo percentual de gordura, a força, manifesta na musculatura definida, na juventude e na sua expressão de sensualidade, resistência e agilidade. Desse modo, todos os corpos se tornam iguais, embora, a intenção de muitos seja dar a ele a percepção de diferença.

\section{CONSIDERAÇÕES FINAIS: POR UMA REFLEXÃO SOBRE A EDUCAÇÃO DO CORPO}

Ao encerrar este texto, deve-se considerar, todas as categorias analisadas não constituem apenas a consciência, mas a consciência do corpo. Não apenas o corpo material, mas acima de tudo, o corpo da consciência, bem como a consciência do corpo.

O corpo se reconhece na sua consciência e a consciência só é possibilitada pela realização do trabalho, conforme é explicado por Hegel (2003). Ao produzir e exteriorizar a consciência, o objeto retorna e permite o reconhecimento de seu criador através do processo da reflexão, visto como o objeto externo constitui a consciência desse corpo. Por outro lado, como a consciência se consolida na relação com o objeto, o corpo sendo externo à consciência e diferente dela deve ser reconhecido como objeto para-si (Hegel, 2003). Destarte, a educação é efetivada e, então, o trabalho consolida o ser humano em suas múltiplas dimensões.

Mas, há de se considerar também o fato de o corpo ser educado em formas históricas particulares. Se todo modo de produção determina as condições de vida, o capitalismo fará a mesma coisa. No entanto, a consolidação do ser humano não se faz da maneira descrita por Hegel (2003), que analisa o vínculo entre o trabalho e a consciência. Nas condições capitalistas, há uma inversão, na qual o homem se converte em ser progressivamente alienado.

Com a divisão do trabalho cada vez mais especializada, o trabalhador passa a realizar apenas parte do trabalho e perde a noção do processo. Perdendo o produto responsável por constituir a sua identidade, o homem não tem o objeto para se refletir e, com isso, perde a si próprio, não se reconhece no seu produto nem no seu trabalho, considerado por ele trabalho forçado. Ele se vê apenas como apêndice da máquina e também parte dela (MARX, 2002). Finalmente, se o indivíduo não se reconhece e se considera um apêndice da máquina, passa a ver o outro da mesma forma, não o reconhecendo como ser humano. As relações não são mais entre os homens, mas entre coisas. O corpo é um elemento fundamental neste processo, conforme afirma Marx (2002), tendo em vista que ele é identificado apenas como máquina. Esse processo se torna mais complexo quando o indivíduo é convertido em apêndice da máquina e se torna uma máquina, fato este, responsável pela reificação humana. 
Através da força de trabalho, o indivíduo insere-se nas relações de produção, tendo em vista o ser livre trabalhador conseguir relacionar-se e negociar a sua jornada de trabalho com o homem livre capitalista. Nesta vinculação realizada entre os dois, o trabalhador vende não apenas a sua força de trabalho, mas a sua vida em troca de salário (MARX, 1996).

A força de trabalho é mercadoria que possui valor de uso para o seu próprio dono; é valor de troca, haja vista que ele troca o tempo de uso desta mercadoria pelo equivalente universal - o dinheiro - para garantir sua existência física. Mas, acima de tudo, essa mercadoria possui valor e depois, torna-se fetiche (MARX, 1996).

Este valor esconde, segundo Marx (1996), um elemento significativo no processo: o trabalho. Dessa maneira, o valor da mercadoria é, na realidade, definido pelo tempo de trabalho humano necessário à sua produção. Logo, se um produto qualquer precisa de vinte horas para ser produzido, ele tem o mesmo valor de outra mercadoria fabricada no mesmo espaço de tempo. Esse raciocínio vale para a força de trabalho, que tem seu valor é definido de acordo com o tempo necessário à sua produção e, destarte, a sua formação para o trabalho e o tempo necessário para isso definem o seu valor.

O corpo, como materialidade humana, entra nesse processo pela sua produção. $O$ trabalhador deve possuir as capacidades físico-mentais, as habilidades intelecto-manuais e o conhecimento teórico-prático para realizar determinadas funções. A realização do trabalho demanda conhecimento próprio. Esse conhecimento assimilado pela consciência do corpo demanda tempo de produção - trabalho - realizado pela pessoa que ensina, de um lado, e pelo próprio sujeito, do outro. A formação do corpo para o trabalho é também trabalho.

Por último, esse valor torna-se irreal, com características fantasmagóricas, ou seja, de acordo com Marx (1996), fetiche. Através dele, o corpo do trabalhador, ao menos enquanto meio de produção, é valorizado de acordo com as competências aprimoradas por ele, embora o preço pago por ele jamais seja realizado plenamente. Caso contrário, existiria a redução dos lucros por parte do capitalista, tendo em vista este sustentar-se pela mais-valia. O corpo é consolidado pelo trabalho humano e é produtivo. Ele é o motor central do capitalismo, porquanto o corpo é o lócus de existência humana, o meio de produção privilegiado, a mercadoria fetichizada a ser reificada. Assim, garante-se o processo de produção e reprodução da vida.

A reificação, anunciada por Marx e analisada de maneira mais específica por Lukács (2003), é a expressão máxima sobre o ser humano da alienação e do fetiche. Ao ser coisificado, o homem passa a ser analisado mais pelos aspectos quantitativos do que pelos qualitativos, considerados secundários neste processo, dado esse justificado pelo processo produtivo. Como o indivíduo trabalhador vende sua mercadoria, sua força de trabalho, ao capitalista durante a jornada de trabalho, definida pelo número de horas de serviço executado, o fator importante é a capacidade de produção desse ser humano. $\mathrm{O}$ trabalhador e seu corpo são a carcaça do tempo a ser utilizada pelo capitalista, por intermédio da qual os aspectos quantitativos são reafirmados. É necessário garantir determinadas condições, entre as quais a manutenção da saúde do trabalhador como forma de reduzir a ausência nos postos de trabalho e, com isso, aumentar a certeza da capacidade produtiva do trabalhador.

Estas qualidades do trabalhador precisam ser checadas pela quantificação das condições apresentadas pelo indivíduo, como a forma do corpo, por meio do percentual de gordura, nível de força, capacidade de resistência entre outras. Esta é uma das formas 
apontadas por Resende (1992) como responsável pela reificação do ser humano. Assim sendo, é definido aqui um modelo de educação baseado na capacidade individual, na quantidade de trabalho a ser realizado e, porque não dizer, no modelo de corpo a ser considerado ideal para a produção.

Todavia, este processo de educação do corpo, vida material do indivíduo, depende da disseminação de idéias da maneira mais ampla possível. Por isso, as informações necessárias, as normas e os valores, como o tipo de corpo adequado à produção, devem ser divulgados para todos e, preferencialmente, devem as pessoas ser convencidas, sentindo-se, ao mesmo tempo, livres para optar de acordo com os seus interesses, muito embora optar entre o branco e o preto não seja liberdade (ADORNO, 1993). Isto é feito em vários espaços, dentre os quais a família e as igrejas. Entretanto, existe um mecanismo mais avançado tecnologicamente e mais afinado com o modo de produção: a indústria cultural.

A indústria cultural apóia-se na racionalidade tecnológica necessária à manutenção da produção e reprodução do modo de produção. Ela contribui para a consolidação da reificação do trabalhador, da sua quantificação bem como da produção e venda de produtos, da massificação das idéias e da cooptação dos indivíduos.

Para além desses objetivos, a indústria cultural invade o tempo livre com a lógica da produção, procurando convencer as pessoas a consumir os produtos fabricados pelo modo de produção. Esse consumo inicia-se pelas necessidades básicas como a alimentação, a higiene e o vestuário, mas o faz, criando outras necessidades, mesmo aquelas consideradas básicas em sua origem, com é o caso da comida e do vestuário. Isso, por um lado, consolida o modelo social vigente e, ao mesmo tempo, mantém principalmente o trabalhador em segurança no seu momento de folga até o retorno ao trabalho (ADORNO; HORKHEIMER, 1985).

A lógica produtiva dissemina-se por todos os espaços sociais, com todos os tipos de mercadoria, inclusive a força de trabalho e o corpo necessário. A idéia de corpo necessário é disseminada com a ajuda das grandes celebridades.

$\mathrm{O}$ culto dos astros do cinema tem como complemento da celebridade o mecanismo social que nivela tudo o que chama a atenção. Os astros são apenas os moldes para uma indústria de confecção de dimensões mundiais e para a tesoura da justiça legal e econômica, com a qual se eliminam as últimas pontas dos fios de linha. (ADORNO; HORKHEIMER, 1985, p. 220)

Os astros do cinema e da televisão funcionam como um grande modelo a ser copiado em suas atitudes, em seus gestos e, ainda, em seus corpos, porquanto a televisão não contrata pessoas feias para trabalharem, a não ser aquelas usadas para expressar as caricaturas e o que não deve ser seguido ou feito. Dentre os exemplos, localizam-se os modelos de corpos a serem seguidos ou não bem como todos os recursos para se alcançar esse padrão.

Essa ação da indústria cultural também se consolida como ato educativo. Definir o modelo de corpo e a estética adequada a essa sociedade faz o indivíduo identificar-se com ações, pensamentos, valores e formas de viver. Dessa maneira, a manutenção da produção e da reprodução consolida a existência do capitalismo.

Com isso, esboça-se o desenvolvimento do problema levantado. A forma do corpo na sociedade capitalista atual é determinada pelos interesses de produção e de consumo do capitalismo. Por um lado, é necessário que o corpo demonstre as possíveis qualidades do dono dessa mercadoria, o corpo força de trabalho, em condições adequadas para se manter no processo de elaboração de bens de consumo. Para atender 
à produção, o corpo deve manifestar certas capacidades como juventude, magreza, força e resistência. Esse modelo, disseminado pela indústria cultural, consolida a educação do corpo como corpo fetichizado. As capacidades entendidas como necessárias, não apenas do ponto de vista do corpo da consciência, mas da consciência do corpo, demandam um processo de construção. O corpo como mercadoria também deve ser produzido, demanda tempo de trabalho e, posteriormente, é vendido como força de trabalho pelo seu proprietário.

Esse corpo é reificado e transformado em coisa, em máquina produtiva, e não é reconhecido como humano. Logo, o ser humano, que não se reconhece como tal, só pode reconhecer o outro dentro desta relação entre coisas. Aí está a importância da mensuração, visto que qualquer máquina precisa ter sua capacidade mensurada para se saber o seu valor. E, assim, como a produção define o consumo, o corpo mercadoria também deve ser consumido, garantindo duplamente a produção. Primeiro, trabalhando ao máximo. Segundo, consumindo inclusive o modelo de corpo na produção e no tempo livre, pois, consumir o modelo de corpo significa investir nele, em sua "saúde", em sua capacidade produtiva e em sua "beleza", para que ele tenha a condição de ser sempre desejado.

São essas as mediações constituídas no modo de produção capitalista. São as mediações constituídas pelo modo de produção que educam o corpo e disseminam a forma considerada ideal. Além do mais, disseminar um modelo de corpo é manter a sociedade administrada de acordo com os objetivos propostos por ela (ADORNO, 2003 e 2006). Porém, consolidar esse modelo é investir na barbárie. A própria competição é uma forma de inserir o corpo nessa lógica, conforme comenta Adorno (2000). Educar para a emancipação implica educar o corpo da consciência e a consciência do corpo. Nessa perspectiva, mais uma vez, Adorno aponta:

[...] em todos os planos de nossa vida, [...], a única concretização efetiva da emancipação consiste em que aquelas poucas pessoas interessadas nesta direção orientem toda a sua energia para que a educação seja uma educação para a contradição e para a resistência. [...] Assim, tenta-se simplesmente começar despertando a consciência quanto a que os homens são enganados de modo permanente, pois hoje em dia o mecanismo da ausência da emancipação é o mundi vult decipi em âmbito planetário, de que o mundo quer ser enganado. A consciência de todos em relação a essas questões poderia resultar dos termos de uma crítica imanente, já que nenhuma democracia normal poderia se dar ao luxo de se opor de maneira explícita a um tal esclarecimento. (ADORNO, 2000, p. 183 -. grifado no original)

Enfim, trabalhar nessa perspectiva educativa em todos os espaços possíveis é insistir na postulação do filósofo frankfurtiano: "A exigência que Auschwitz não se repita é a primeira de todas para a educação” (Adorno, 2000, p. 119).

\section{ABSTRACT}

In recent times, the body has become an ever more frequent object of study. So this study sets out to discuss the education of the body under capitalism, and especially in our present society. 
The question is asked: "How is the shape of the body determined in our present capitalist society?" The aim is to identify how the mediations to determine the shape of the body are established under this mode of production. The theoretical references used are those of Karl Marx, Theodor Adorno, Max Horkheimer and Georg Lukács. This theoretical study shows that the production and consumer interests of the capitalist production mode determines the shape of the body.

Key-words: Body work. Culture industry. Education.

\section{NOTAS}

${ }^{1}$ A menção específica à educação física se justifica pelo fato de ser esta a área de conhecimento vinculada à Educação mais próxima deste debate, tendo-se em vista o foco da área para o tratamento das questões corporais, tanto do ponto de vista biológico como do ponto de vista cultural e social.

${ }^{2}$ Devido aos limites de um artigo não é possível esgotar todos os assuntos necessários, por isso, sugere-se a leitura do Capítulo 1, de Marx (1996), para a compreensão, de maneira mais detalhada, o desenvolvimento do valor da mercadoria.

\section{REFERÊNCIAS}

ADORNO, T. W. Indústria cultural e sociedade. 3. ed. São Paulo: Paz e Terra, 2006.

. Sobre a indústria da cultura. Coimbra: Angelus Novus, 2003.

. Educação e emancipação. 2. ed. Rio de Janeiro: Paz e Terra, 2000.

. O fetichismo na música e a regressão da audição. São Paulo: Nova Cultural, 1999, p.65-108. (Coleção Os Pensadores).

Palavras e sinais: modelos críticos 2. Petrópolis: Vozes, 1995.

. Minima moralia: reflexões a partir da vida danificada. São Paulo: Ática, 1993.

; HORKHEIMER, M. Dialética do esclarecimento: fragmentos filosóficos. Rio de Janeiro: Jorge Zahar, 1985.

BAPTISTA, T. J. R. Procurando o lado escuro da lua: implicações sociais da prática de atividades corporais realizadas por adultos em academias de ginástica de Goiânia. Dissertação (Mestrado em Educação). Goiânia: UFG, 2001.

DESCARTES, R. O discurso do método. São Paulo: Abril Cultural, 1973, pp. 25-71. (Coleção Os Pensadores).

GOLDMANN, L. A reificação. In: Dialética e cultura. 2. ed. Rio de Janeiro: Paz e Terra, 1979, pp. 105-52.

GONÇALVES, M. A. S. Sentir, pensar, agir: corporeidade e educação. Campinas: Papirus, 1994. 
GRANDO, J. C. (Org.). A (des)construção do corpo. Blumenau: EDIFURB, 2001.

As concepções de corpo no Brasil a partir de 30. In: (Org.). A (des)construção do corpo. Blumenau: EDIFURB, 2001.

HEGEL, G. W. F. Fenomenologia do espírito. 2. ed. rev. Petrópolis/Bragança Paulista: Vozes/USF, 2003.

LUKÁCS, G. A reificação e a consciência do proletariado. In: LUKÁCS, Georg. História e consciência de classe: estudos sobre a dialética marxista. São Paulo: Martins Fontes, 2003, p.193-411.

MARX, K. Manuscritos econômico-filosóficos. São Paulo: Martin Claret, 2002.

A miséria da filosofia: resposta à filosofia da miséria de Proudhon (1847). São Paulo: Centauro, 2001.

O Capital. São Paulo: Nova Cultural, 1996, v. 1. (Coleção Os Economistas).

RESENDE, A. C. A. Fetichismo e subjetividade. São Paulo: Pontifícia Universidade Católica, 1992. (Tese de Doutorado em Ciências Sociais)

ROUANET, S. P. O homem-máquina hoje. In: NOVAES, Adauto. O homem-máquina: a ciência manipula o corpo. São Paulo: Companhia das Letras, 2003, p.37-64.

SILVA, A. M. Corpo, ciência e mercado: reflexões acerca da gestação de um novo arquétipo da felicidade. Campinas/Florianópolis: Autores Associados/Ed. da UFSC, 2001.

SOARES, C. L. Educação Física: raízes européias e Brasil. 2. ed. rev. Campinas: Autores Associados, 2001.

VÁZQUES, A. S. Filosofia da práxis. Rio de Janeiro: Paz e Terra, s.d.

Tadeu João Ribeiro Baptista é doutor em Educação pela UFG, professor dos Cursos de Graduação em Educação Física da ESEFFEGO e da UCG e professor do Mestrado em Ciências Ambientais e Saúde. E-mail: tadeujrbaptista@yahoo.com.br

Anita Cristina Azevedo Resende é professora da Faculdade de Educação, onde integra o Programa de Pós-Graduação em Educação da Universidade Federal de Goiás.

E-mail: aazeres@uol.com.br 